\title{
Sistema de Controle de Vazão de Líquidos para Aplicações em Medições de Reações Biológicas
}

Cavalcanti, G. O.

Escola Politécnica de Pernambuco

Universidade de Pernambuco

50.720-001 - Recife, Brasil

gustavooc@poli.br

\author{
Oliveira, R. M. \\ Escola Politécnica de Pernambuco \\ Universidade de Pernambuco \\ 50.720-001 - Recife, Brasil \\ morais_morais10@hotmail.com
}

Resumo Este trabalho apresenta o desenvolvimento de um sistema controlado por computador que produzirá um fluxo laminar contínuo pressionando o êmbolo de uma seringa. O sistema construído será acoplado ao reflectômetro automático [1] do Grupo de Fotônica da UFPE e possibilitará a análise de reações biológicas. O sistema foi dimensionado para obter fluxo laminar e um aplicativo desenvolvido em $\mathrm{C}++$ realiza o controle da vazão e permite definir a proporção de cada fluido nos experimentos.

\footnotetext{
Abstract This paper shows the development of a computercontrolled system that will produce a continuous laminar flow by pressing the plunger of a syringe. The system will be coupled with an automatic reflectometer [1] of the Photonics Group at UFPE and make possible analysis of biological reactions. A software was developed in $C++$ to flow control and allows to define the proportion of each fluid in the experiments.
} 


\section{Introdução}

O sistema de controle de fluxo é composto pelas peças automatizadas onde são encaixadas as seringas, pelo modulo controlador e por um computador onde fica hospedado o software de controle, conforme Fig.1. O software serve como interface para o usuário do sistema, o módulo controlador se comunica com o computador através da porta serial USB e controla os motores de passo (MP) [2], que atuam nos êmbolos dos cilindros, e assim produzem o fluxo no tubo de saída dos cilindros, como apresentado na Fig.1. Uma peça especial, que não faz parte deste projeto, será desenvolvida para que o fluxo seja integrado ao

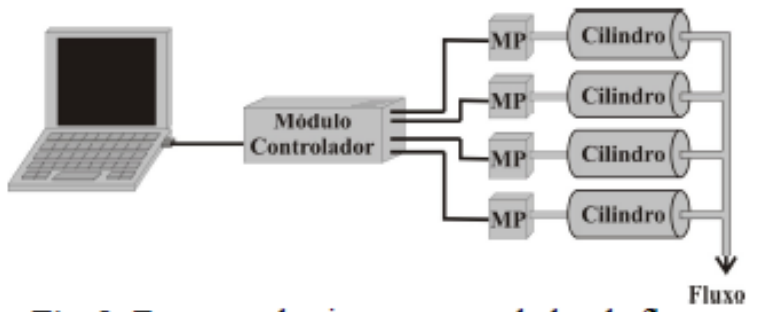

Fig. 1. Esquema do sistema controlador de fluxo.

reflectômetro, através do qual será possível a caracterização de reações biológicas.

O software possuirá uma interface gráfica que facilitará a utilização do sistema. O principal componente do módulo controlador é o microprocessador PIC 18F4550 [3, 4] responsável pela comunicação serial USB com o computador, e suas portas de saída realizarão o controle dos motores de passo. Cada motor de passo será acoplado ao êmbolo de um cilindro que inicialmente conterá o líquido, mas que será expulso à medida que o êmbolo for empurrado pelo motor.

\section{Sistema de Controle Fixo}

No sistema de fluxo o cilindro apresentado na Fig.1 é uma seringa comercial que poderá possuir tamanhos diferentes. A vazão provocada pelo deslocamento do êmbolo da seringa em função da velocidade de deslocamento do êmbolo é

$$
Q=\pi r^{2} v
$$

onde $r$ é o raio do cilindro (seringa) e $v$ é a velocidade do êmbolo $[5,6]$ que é controlada pela velocidade de rotação do motor de passo. A velocidade do fluido em um ponto " $A$ " da tubulação pode ser determinado por

$$
v_{A}=Q / S_{A}
$$

onde $S A$ é a área da secção transversal por onde passa o fluido $[5,6]$.

O controle do fluxo e da velocidade do fluido é realizado pelo software hospedado no computador utilizando as equações apresentadas em (1) e (2) e os parâmetros de dimensões da seringa. O sistema possui dois softwares: o primeiro é a interface gráfica do sistema que é executado no computador e serve tanto para fazer os cálculos necessários para a movimentação dos motores quanto como uma interface para o usuário e o segundo está hospedado no microprocessador PIC do módulo controlador e é responsável pela movimentação básica dos motores (sentido, velocidade e distância).

\subsection{Interface Gráfica do Sistema}

O software de interface gráfica do sistema está em fase de conclusão e foi desenvolvido com um pequeno número de comandos, mas que possibilita ao operador controlar totalmente o sistema e montar diversos experimentos. A Fig. 2 apresenta a interface gráfica do software que é responsável por capturar, processar e enviar os comandos de controle dos motores via USB para o microprocessador. O processamento dos comandos é feito no computador de acordo com o pseudocódigo a seguir.

- Pseudocódigo para processamento dos dados de entrada do software

1. Entrada: Quantidade de líquido esperada, Tempo.

2. Calcule o espaço a ser percorrido pelo êmbolo do cilindro.

3. Calcule a quantidade de passos a ser dada pelo motor.

4. Calcule o tempo necessário de intervalo entre cada passo.

5. Envie os dados para o microprocessador PIC. 


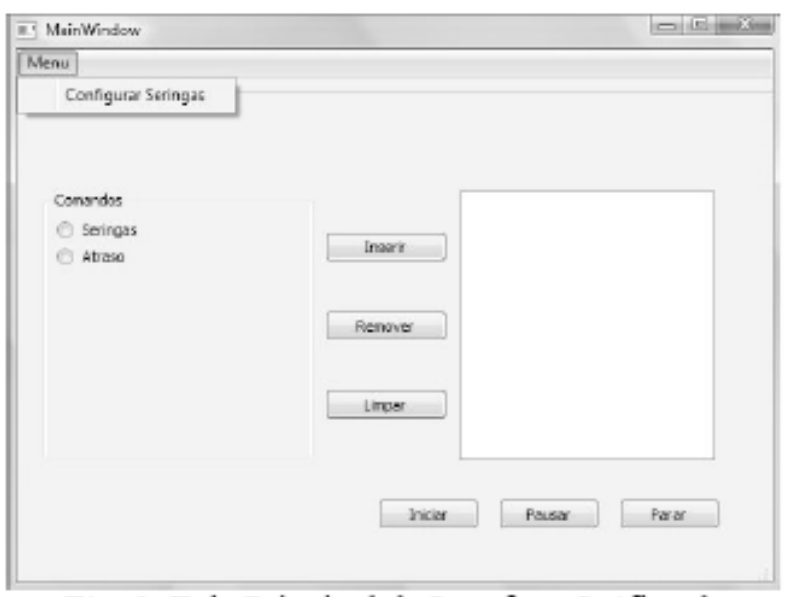

Fig. 2. Tela Principal da Interface Gráfica do sistema.

\subsection{Módulo Controlador}

O módulo controlador fornece os níveis de corrente e tensão adequados para o funcionamento e os sinais para o controle dos motores de passos [2]. Um microprocessador PIC 18F4550 [3, 4] recebe as informações do software de interface e controla os motores de passo. O software do microprocessador PIC foi desenvolvido utilizando o compilador CCS, da linguagem de programação "C". Este software controla a movimentação primária dos motores de acordo com o cálculo feito pelo software de interface, que é responsável por tratar a entrada do usuário, fazendo os cálculos necessários. O Pseudocódigo do software do microprocessador está apresentado a seguir.

- Pseudocódigo para execução dos comandos de controle do motor

1. Entrada: Quantidade de passos, Intervalo entre cada passo.

2. Para cada iteração da quantidade de passo Faça

3. Atribua o número binário correspondente para cada saída do PIC.

4. Espere o intervalo entre cada passo.

\section{Fim do Para.}

O circuito do módulo controlador foi desenvolvido e simulado no aplicativo "Proteus" para testes antes da montagem no Protoboard, conforme apresentado na Fig. 3. A utilização desta plataforma de simulação foi importante tanto para o desenvolvimento do módulo controlador como também do software de controle hospedado no PIC, pois ela permite a integração do circuito montado com um possível código a ser gravado no microprocessador.

Após os testes de simulação, foram identificados e

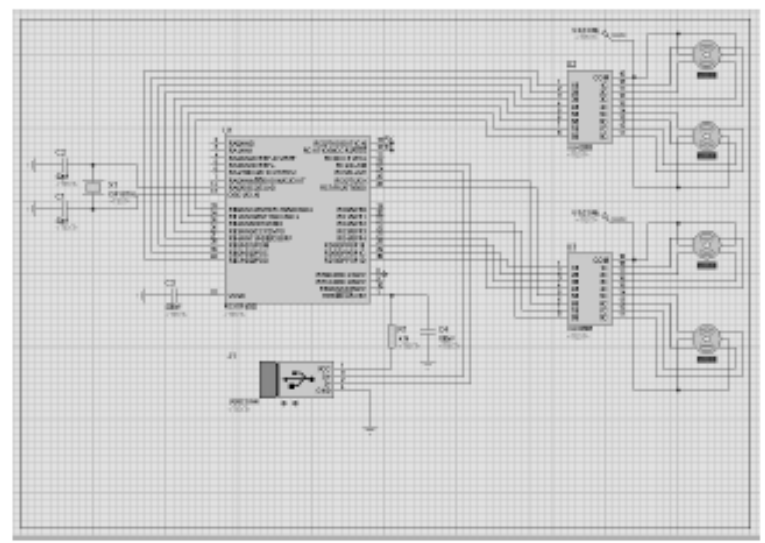

Fig. 3. Módulo de controle desenvolvido na plataforma de simulação "Proteus".

adquiridos os componentes necessários para a montagem do módulo controlador, que são:

- 1 - PIC18F4550;

- - ULN2803;

- $\quad 1$ - Crystal (20MHz);

- 1 - Resistor (4.7k);

- 1 - Capacitor $(100 \mathrm{nF})$;

- 1 - Capacitor $(200 \mathrm{nF})$;

- $\quad$ Capacitores $(22 \mathrm{pF})$.

Após aquisição dos componentes o circuito do controlador foi montado em um protoboard. Novos testes foram realizados no circuito em protoboard, antes de começar a confecção da placa de circuito impresso, conectorização dos motores de passo e encapsulamento, para colocar o circuito em uma caixa protetora.

Foi realizada uma analise dos motores de passo disponíveis quanto ao torque necessário, tensão e corrente. Para o desenvolvimento das peças de acoplamento foi feita uma análise de algumas peças já pertencentes ao grupo de Fotônica da UFPE, e também de algumas máquinas semelhantes [7, 8, 9]. Após esta análise foi realizado o projeto das peças necessárias para a integração dos componentes mecânicos do sistema. 


\section{Peças Motorizadas}

Foi realizada a análise do torque necessário para o motor de passo a ser utilizado e o passo do parafuso acoplado ao eixo deste motor, para atingir a precisão apresentada pelos dispositivos encontrados na literatura [7, 8, 9]. Assim como a capacidade de armazenamento do PIC, para conhecer a quantidade de memória que o software pode ocupar.

Todas as relações matemáticas dos componentes mecânicos que dizem respeito ao funcionamento do sistema já foram projetadas, bem como o algoritmo principal que é responsável pela movimentação dos motores, e a interface gráfica que pode ser observada na Fig. 2, e integrará as entradas passadas pelo usuário à parte lógica do sistema. Restando apenas a realização de algumas definições no algoritmo responsável pela movimentação dos motores e a confecção das peças mecânicas que serão realizadas na oficina mecânica do departamento de Física da UFPE.

O sistema será capaz de controlar o fluxo em quatro seringas simultaneamente. $\mathrm{O}$ projeto das peças mecânicas motorizadas já foi concluído e a Fig. 4 apresenta uma ilustração da estrutura que será construída.

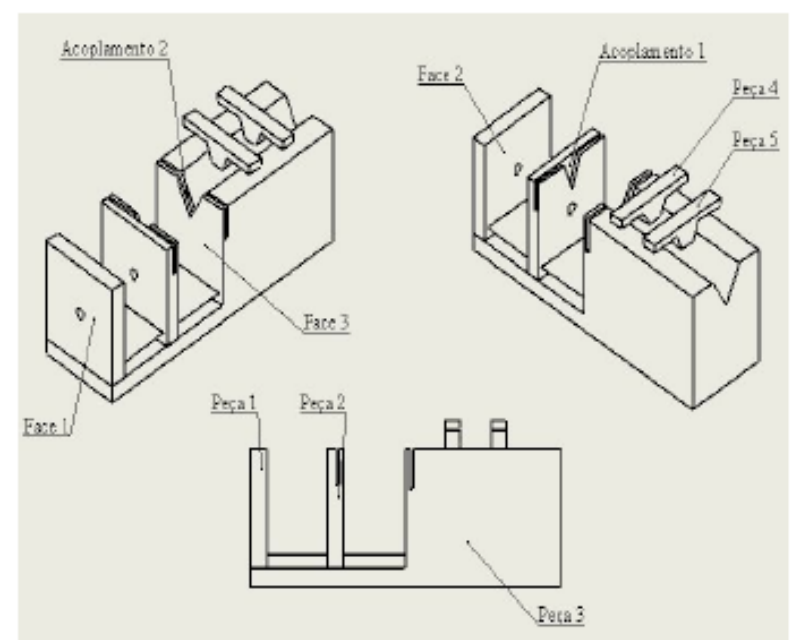

Fig. 4. Esquema de montagem das peças de acoplamento.

O motor de passo será fixado na Face 1 e o parafuso sem-fim que será colocado no seu eixo, transpassará as Peças 1 e 2 até chegar na Face 3, conforme ilustrado na Fig.4. O êmbolo da seringa será encaixado no Acoplamento 1, pertencente a Peça 2, esta que se movimentará, de acordo com a rotação do parafuso sem-fim, entre as Faces 2 e 3 de maneira a comprimir o êmbolo. No Acoplamento 2 será encaixada a base da seringa, e as Peças 4 e 5 servirão para fixar essa base.

\section{Conclusão}

O projeto do sistema capaz de gerar um fluxo laminar de um líquido não viscoso, a temperatura ambiente e em baixas pressões foi realizado. O sistema será confeccionado e acoplado ao reflectómetro pertencente ao grupo de Fotônica da UFPE para possibilitar a caracterização de reações biológicas.

Todos os resultados obtidos até o momento estão de acordo com o planejamento. $\mathrm{O}$ circuito já foi projetado e construído em protoboard, as peças de acoplamento do motor de passo ao embolo do cilindro já foram projetadas, o software de interface com o usuário que precisou ser desenvolvido por último e o software do microprocessador, já estão em fase de conclusão.

\section{Referências}

[1] CAVALCANTI, Gustavo Oliveira. Reflectômetro controlado por computador e sua aplicação na detecção de hidrogênio com filmes finos de paládio e ouro/paládio. Dissertação, Universidade Federal de Pernambuco.

[2] MESSIAS, Antonio R. Disponível em: <http://www.rogercom.com/pparalela/IntroMotorPasso.htm> . Acesso em: 22 Mar. 2011, 14:05:45.

[3] IBRAHIM, Dogan. Advanced PIC microcontroller projects in C: from USB to RTOS with the PIC18F series. Burlington: Elsevier, 2008.

[4] PEREIRA, Fábio. Microcontroladores PIC: Programação em C. São Paulo: Érica, 2003.

[5] Mecânica dos Fluidos. Disponível em: <http://200.210.165.28/mecanica/ciclo4/Mecanica_dos_Fluid os.pdf>. Acesso em: 22 Mar. 2011, 14:10:37.

[6] Mecânica dos Fluidos. Disponível em: <http://www.hidro.ufcg.edu.br/twiki/pub/Disciplinas/Fen\%F 4menos DeTransporte/Texto03.pdf>. Acesso em: 22 Mar. 2011, $14: 13: 24$.

[7] Samtronic Infusion Systems. Disponível em: <http://www.samtronic.com.br/site/>. Acesso em: 22 Mar. 2011, 13:55:30.

[8] Lambda Laboratory Instruments. Disponível em: $<$ http://www.lambda-instruments.com/?pages= 
portuguesebomba- de-seringa>. Acesso em: 15 jul. 2011, 10:25:43.

[9] KD Scientific. Disponível em: <http://www.kdscientific.com/products/pumps/LegatoProgra mmablePush Pull.asp>. Acesso em: 15 jul. 2011, 10:47:33. 